vein, which also felt knotty, and looked somewhat red, just sbove the origin of the tendo Achillis.

On the sixth day he had just a show of blood in his expectoration, and from this date he began to show signs of improvement. The dulness in lung gradually cleared up, and but for the pain and weakness of right leg he felt fairly well, when he left this neighbourhood for Kent, which he was able and obliged to do about five weeks from the commencement of his illness.

CASE 3.-George J-, a tall, broad-chested Scotch footman, consulted me for symptoms which were anything but definite-namely, weakness, languor, anorexia, and slight cough. On account of the latter I examined his chest, but found nothing to lead me to suspect pulmonary mischief. When he had been under treatment about a week he had a smart hæmorrhage from the lungs, and on examining his chest a second time, I found well-marked consolidation of the upper part of the left lung. The hæmorrhage lasted during one day, and there was slight dyspncea, but no intensitication of the other symptoms. To his general symptoms of malaise were added in the course of the next few days increased cough, night-sweats, a rise in temperature, and I must say his case looked like one of incipient phthisis. To favour this idea, he had well-marked filbert-shaped nails, but he maintained that back even to the third generation there was no history of phthisis in his family.

Ten days after the hæmoptysis, pain of an intense crampy nature appeared in the calf of his left leg; the limb felt painful to the touch, and like to burst when put to the ground. In the lower part of the calf of the leg, the saphenous vein was well-defined, painful when touched, marked along its course by a pinkish blush, and filled by a chain of embolic clots.

Under appropriate treatment this knotted and phlebitic state of the vein disappeared in the course of ten days, though the circulation of the leg remained weak, and had to be supported by careful bandaging for some time.

Six weeks after the hæmorrhage the general symptoms remaining were those apparently of phthisis-viz., debility, cough, loss of flesh, dulness in upper lobe of left lung, shortness of breath when walking up stairs, with a pulse about 90 and a mean temperature of $100^{\circ}$. Phthisis it may eventually turn out to be, but the initial symptoms it must be confessed show considerable divergence from the usual course of this disease, and I think I am justified in recording it in the same category as the others-viz., peripheral thrombosis with embolism, the embolic complication in this case, as in the second, being hrmorrhagic infarction of the lung.

In the origin and grouping of the symptoms we have the recognised elements of this pathological state, because there were (I) undoubted evidence of thrombosis and embolism, the latter accompanied by its characteristic dyspncea; (2) the capillary hæmorrhage, a hæmoptysis characteristic as to onset, quantity, and colour ; (3) hæmorrhagic transudation into upper lobe of lung, as evidenced by the dulness on percussion ; (4) and this ending in a low form of pneumonia, with a mean temperature of not more than $100^{\circ}$.

Gerhardt ${ }^{1}$ says "the diagnosis of hæmorrhagic infarction is easy to make in most cases, especially in cardiac cases, aud in cases of thrombosis of the crural veins or those of the calf"; and, further, that the diagnosis may be "determined if there obviously exist embolic material and an embolic attack, and when the diagnosis is confirmed by absence of fever, dulness in the lower lobe, lasting for some weeks, and hæmoptysis."

Feltz has also pointed out that hremorrhagic infarction of the lung always originates in hæmorrhage, resulting from rupture of the capillaries. And, again, according to Gerhardt, "the earliest and truest of the symptoms of the hrmorrhagic infarction is spitting of blood"; and this hæmoptysis may be pure blood, as noticed by Laennec, Dettrich, and others.

Hæmorrhagic infarction is not necessarily pneumonic, but, according to Rindfleisch, ${ }^{2}$ it " is merely a preliminary to the actual inflammation, and is the first result of the embolism, the inflammation (embolic pneumonia) being as something superadded or secondary." It might be objected that in this case the embolic symptoms proper did not appear till ten days after the hæmoptysis and the lung deposit,

1 German Clinical Lectures, page 277.

2 Pathological"Histology, vol. ii., p. 67 . whereas it ought to have taken precedence in point of time. But as embolism may be so urgent and pronounced as to cause sudden death itself, it may nevertheless be so masked and of such a degree as to " occur almost or altogether without symptoms" (Gerhardt). Having the embolic material there, the sudden lung deposit appearing with dyspnoea after the hæmoptysis, coupled with the important point of a nonpneumonic temperature, we have, I think, a right to conclude that the first embolic act leading to the infarction passed unnoticed. To throw a final stone on the cairn of evidence, I would quote again from Gerhardt, who says : "It is indeed frequently the supervention of infarction of the lungs which first gives a certain basis for the diagnosis of thrombosis."

In my first case, that of Mr. C- the chain of distinctive symptoms is more complete, for (1) there was the congestive attack over or near the external iliac vein. And here I may be allowed to quote Trousseau ${ }^{3}$ on the probable results of such a complication: "It is a remarkable fact that frequently, as soon as there is an obstacle to the venous circulation, fibrine is precipitated, so to speak, into the valvular pouches, giving rise to the knots in the course of the veins. There were (2) the sudden cramp and other decided symptoms of venous obstruction in the leg of the same side. (3) the presence of the thrombus and embolus in the popliteal space ; (4) the attack of dyspnœea and subsequent bloody sputum ; (5) the resulting oedema of the limb.

In the second case, that of the gouty butler, the symptoms of embolic infarction are still more pronounced; for-(1) In the presence of gout and the fact of the blister over or near the origin of saphenous vein, we have the dyscrasia,. "the pathological aptitude," or tendency to this complication; (2) the decided fact of the embolic act, as seen in the dyspnoa inability to lie down, sudden crampy pain in calf of leg, embolic knots in saphenous vein; (3) hæmoptysis of pure blood, followed by dulness in lower lobe of left lung, a slowly developed lobar consolidation, with comparatively low, at least non-pneumonic, temperature.

It is worthy of remark that in the last two cases the hæmoptysis appeared to be the initial symptom, but the pain in calf and appearance of emboli in the limb must, of course, be held to represent a repetition of the embolic act, which subsequently led to the hæmorrhagic infarct. And, of course, an embolus cast adrift from a thrombus, before it could reach the pulmonary artery, must be supposed to travel straight to its destination, without causing obstructive symptoms by the way. Indeed, in all the three cases, there must have been repeated embolic acts, causing hæmoptysis and lung deposit on the one hand, or, being arrested by the way, causing obstructive symptoms in the veins in the other.

Clinically speaking, these cases in their more salient symptoms form a synthesis undoubtedly leading up to embolism, and a rough analysis of those same symptoms, still more decidedly, points to this vascular obstruction as being their true and only rational pathology.

Nothing, I think, need be added as to the great and urgent importance of an early recognition of such cases: for anyone must see that if a phthisis or a pneumonia owes its origin to embolism, the danger of a sudden and deplor. able contretemps is increased tenfold.

Rothwell, Northamptonshire.

\section{FOREIGN BODY IN THE RIGHT BRONCHUS; EXPULSION ON THE ONE HUNDRED AND SECOND DAY.}

\section{$\mathrm{BY}$ H. B. YOUNG, A.M., M.D.}

THE report of the following case was suggested by the article on a similar subject by W. Beattie Smith, L.R.C.P.E.y in THE LANCET of June 28th, 1879. It occurred in this place some fifteen years since in the practice of my father Dr. John A. Young (now deceased), and has never been published.

On Sunday evening, April 24th, 1864, W. C-_, a bright boy aged five years, while playing with an oval glass-bead three-quarters of an inch in length and one-quarter in 
idth, perforated longitudinally, put it in his mouth, and, in attempting to bite it, it suddenly slipped from between his teeth and found its way into the right bronchus. The usual means for dislodging, inversion, shaking, \&c., were immediately resorted to, and during the course of the evening several times repeated, but all without effect. As the dyspncea was not great, however, and the child in no particular distress, it was resolved, as in the case reported by Mr. Beattie Smith, to temporise. If an operation should prove to be necessary, the conditions would certainly be none the worse for a little rest.

The following morning, after another unsuccessful repetition of the inversion process, it was agreed, in consultation with other physicians present; that tracheotomy, with a view to extraction, was the most promising course, and it was accordingly done. But with all the forceps to be had, and a slender probe hooked at the extremity and introduced after the forceps, all attempts for the removal of the obstacle were equally unsuccessful. That the bead was far from stationary was clearly demonstrated. A cough being induced, it could be heard to come up into the trachea with a bound, to sink back again on deep inspiration when the cough ceased. The hope was then entertained that another visit might find a different situation of affairs-the bead possibly lodged within easy reach of the forceps. The tube was therefore inserted, and the wound dressed.

Three or four visits were made daily after this, but nothing of importance occurred until the fourth day (Friday), when at 11 o'clock A.M. there was a sudder, and although lasting only a few minutes, a serious hæmorrhage. The tracheal wound was at once examined, but the trouble was evidently at some point below, as this was found in excellent condition. At 11 o'clock P.M of the same day a second and much more serious hæmorrhage followed; indeed so serious was it, that after the air-passages were once cleared, and the child laid down, it was thought he would immediately die, so great was the exhaustion from loss of blood. He rallied, however, after a time; and there being no return of the hæmorrhage by morning, he was comparatively comfortable, though very weak. That evening (Saturday), it being deemed unsafe to further irritate by any attempts at extraction, and the child having fretted considerably over his inability to speak aloud, the tube was removed, and the treacheal wound closed up. Absolute quiet for some days to come, and a careful attention to nourishment, being the pressing necessities, all other proceedings were left for time and events to determine. With the closure of the tracheal wound came the whistling respiration mentioned in Mr. Beattie Smith's case, which in like manner was attributed to the passage of air through the opening in the bead. This was present so long as the bead remained in the bronchus.

From this time on there was little active interference with the case. The recovery from the effects of the hremorrhages was rapid, and with the exception of some dyspnoea after lively play, and an unequal chest expansion, the left side apparently doing all the work, the child seemed fairly well.

On Wednesday evening, August 3rd following, 102 days after the accident, a sister of the boy came running to say that the bead had been expelled. A call at the house at once showed this to be true. It appeared from the story of the boy himself, as well as that of the older ones with him, that he had had a sudden fit of anger in his play, and had thrown himself headforemost over the end of a reclining lounge which stood near; that in this position, with his feet up and his head down in giving vent to a terrific cry, the bead shot from his mouth with such velocity as to carry it some four or five feet away across the floor. It was not at first known to be the bead, but on picking up the object which in flying out of his mouth had so suddenly stopped the boy's crying, and wiping off the mucus which covered it, it was found to be that troublesome article. More than this was discovered. At one end of the bead, instead of the usual smooth surface surrounding the opening, was an uneven facet, the result of a chipping. At one side of this facet was a moderately sharp projection, doubtless the cause of the hæmorrhages.

Of the subsequent history of the case there is none. The child had no further attention, thrived, and grew to be what I saw him yesterday, a strong, hearty, and welldeveloped young man.
In conclusion, I have only to add my regrets that I am unable to give a more detailed account of this very interesting case. Among my father's papers I find but little about it, and the memory of those connected with it does not reach with accuracy to such matters as temperature, chestsounds, amount of blood lost (which must have been considerable) at the two hæmorrhages, \&c., which it would be desirable to know. That the case might prove interesting with an enumeration only of the most important occurrences, and instructing from the sufferance it shows in a young and healthy lung, which, after three months of obstruction, entirely regains its efficiency, is my apology for presenting it in this imperfect manner.

Monmouth, Illinois, U.S.A.

\section{SOME EFFECTS OF POISONING BY ALCOHOL.}

\section{BY W. T. PARKER DOUGLAS, B.A., M.B.}

THE following data of a case which has recently terminated fatally may be of interest to others, as it has been to myself, inasmuch as it exhibits some uncommon occurrences produced by the persistent imbibition of ardent spirit.

The subject of these remarks was the wife of a retired farmer and landed proprietor, the mother of five children, and thirty-six years of age. For seven years she had been addicted to intemperance (which appears to have been hereditary). On two or more occasions she had delirium tremens, and but rarely, and only for short intervals, was either temperate or abstained altogether. For a period of eight weeks prior to her decease she was sober only nine or ten days, and the quantity per diem consumed varied to a maximum of four pints of raw spirit (either brandy or whisky).

The first effect of drinking with her was violent heartaction, followed by almost imperceptible pulsation. Then stupor, from which she awoke to a sense of chilliness and shivering, with nausea, but no vomiting, and never complained of headache. During the last eight days of life she was helpless to do anything for herself, and took but little stimulant, for which she had then a loathing. Five days prior to death the skin was sallow, face bloated, tongue dry, furred, and brown; sordes on teeth and lips; nasal mucous membrane dry, and bleeding occasionally ; intense gastric pain, with violent retching and vomiting of "coffeegrounds" matter; abdominal distension and tympanites; liver dulness diminished; the excretion from the bowels principally of digested blood; urine scanty, and deeply coloured with bile; in addition to the hæmorrhage from the nose, stomach, and bowels, there was also bleeding from the uterus and from the left ear. 'Two days later superficial gangrene commenced in spots on the pinna of the left ear, and on the cheek an inch above the left angle of the mouth. The former was localised, but the latter extended and involved first the upper lip, and, spreading upwards, included the skin of the nose and adjoining portions of both cheeks to the margin of the lower eyelid on the right side, and across the bridge of the nose, affecting both lids of the left eye, which was closed, and the lids glued together by secretion: thus forming almost a circle which would correspond pretty accurately to the surface covered and included by a glass tumbler, as in the act of draining the last dregs of its contents.

The localisation of the gangrene was, at least, peculiar, but of the cause of its determination to that particular portion of skin I am not prepared to offer an opinion, though I cannot but think that, in drinking, the alcoholic vapour may have been an element in its causation. The patient made no complaint of pain in the face; in fact, for forty. eight hours prior to death, she was perfectly conscious and free from pain, and only distressed with weariness, Diarrhoea at last set in, and the pulse, which for three days beat at the rate of 140 to 150 in the minute, gradually grew fainter. I may add that nowhere else but in the parts in. dicated was there a spot of gangrene.

Newbury. 